University of Massachusetts Amherst

ScholarWorks@UMass Amherst

1984

\title{
Determination of Chromium in Steel by Flame Atomic Absorption Spectrometry using a Flow Injection Standard Additions Method
}

Julian Tyson

University of Massachusetts Amherst

A. B. Idris

Loughborough University of Technology

Follow this and additional works at: https://scholarworks.umass.edu/chem_faculty_pubs

Part of the Chemistry Commons

\section{Recommended Citation}

Tyson, Julian and Idris, A. B., "Determination of Chromium in Steel by Flame Atomic Absorption Spectrometry using a Flow Injection Standard Additions Method" (1984). Analyst. 1286.

Retrieved from https://scholarworks.umass.edu/chem_faculty_pubs/1286 


\title{
Determination of Chromium in Steel by Flame Atomic-absorption Spectrometry Using a Flow Injection Standard Additions Method*
}

\author{
Julian F. Tyson and Ahyar B. Idris \\ Department of Chemistry, Loughborough University of Technology, Loughborough, Leicestershire, \\ LE11 3TU, UK
}

\begin{abstract}
The determination of chromium in steel by atomic-absorption spectrometry is briefly reviewed and the basis of the flow injection standard additions method explained, in which the novel configuration of using the sample as the carrier stream is employed. The effects of iron, fuel to oxidant ratio and dissolution procedure were investigated and a procedure is described that allows a conventional instrument-optimising strategy to be used, requires no releasing agents and uses pure chromium standard solutions. The selection of appropriate flow injection conditions is discussed in the light of the single well stirred mixing chamber model for dispersion. The application of the method is demonstrated by the analysis of six British Chemical Standard steels.
\end{abstract}

Keywords: Flow injection analysis; standard additions method; atomic-absorption spectrometry; chromium determination; steel analysis

The determination of chromium in steel by atomic-absorption spectrometry with an air-acetylene flame has been extensively studied ${ }^{1-9}$ and is reported to be subject to a large number of interference effects. The factors that affect the slope and shape of the calibration graph include the presence of iron, the nature of the acids used for dissolution, the oxidation state of the chromium and the flame stoicheiometry.

A variety of methods for overcoming these interferences have been proposed, including the addition of releasing or suppressing agents, ${ }^{3,5,6,7,9}$ separation and solvent extraction, 2,4 matrix matching, $1,8,10,11$ the use of the dinitrogen oxide - acetylene flame $8,10,11$ and the use of a plasma. ${ }^{12}$

The interference effects of iron and acids on the chromium signal have been studied under various flame conditions. , $^{73-15}$ The depressive effect of iron and the releasing action of ammonium chloride $7,13,14$ and quinolin-8-ol-6 have been discussed. The mechanisms of the interference from acids ${ }^{15}$ and the effects of other cations ${ }^{16}$ have also been explained in great detail. The effects of the oxidation state of chromium on the calibration graph have also been investigated. ${ }^{17,18}$ Most reports ${ }^{3,5-9,12}$ have advocated the use of a mixture of hydrochloric and nitric acids for sample dissolution, although various other acid mixtures have been used, 1,2,4,10,11

In this paper, the use of a flow injection-based analogue of the standard additions method is described. This approach avoids the need to use releasing agents and considerably simplifies the volumetric manipulations of the conventional standard additions procedure, as the dispersion produced between the point of injection and the nebuliser can be designed to mimic the addition of standards to the sample followed by dilution to volume. A simple model for the dispersion behaviour observed in flow injection - atomic-absorption systems, based on considering all the dispersion to be produced by a single well stirred mixing chamber, has been proposed ${ }^{19.20}$ and the use of this model to calculate the concentration of interferent appropriate for a given calibration sequence and dispersion has been described for the flow injection analogues of matching standard ${ }^{21}$ and standard additions ${ }^{21.22}$ methods. In the flow injection standard additions method the reverse configuration to the normal methods of flow injection analysis is used, in that the sample is used as the carrier stream into which are injected discrete volumes of the pure standards. The

\footnotetext{
${ }^{*}$ Presented at the Royal Society of Chemistry Analytical Division meeting on "Research and Development Topics in Analytical Chemistry," held at Loughborough University of Technology on March 28th and 29th, 1983.
}

dispersion is designed (by suitable selection of volume injected and carrier tube dimensions) so that at the peak maximum (the measurement point) the appropriate ratio of interferent to analyte is achieved. The calculation takes account of the dilution of (a) the injected standard, (b) the analyte in the carrier and (c) the interferent in the carrier. As with all standard additions methods, the interferent to analyte ratio above which the depressive effect becomes constant must be known for the successful application of the method. The relationship between the relevant parameters is

$$
C_{\mathrm{m}}^{\mathrm{R}}=\left[C_{\mathrm{t}}^{\mathrm{S}} /(D-1)+C \mathrm{X}\right] R_{\mathrm{i} / \mathrm{a}}
$$

where $C_{\mathrm{m}}^{\mathrm{R}}$ is the concentration of interferent in the sample carrier stream, $C_{\mathrm{t}}^{\mathrm{S}}$ is the concentration of the top standard injected in the calibration sequence, $D$ is the dispersion, $C^{\mathrm{x}}$ is the concentration of the analyte in the sample carrier stream and $R_{\mathrm{i} / \mathrm{a}}$ is the minimum ratio of interferent to analyte necessary to achieve the maximum interference.

\section{Experimental}

\section{Apparatus}

This was as described previously. ${ }^{22} \mathrm{An}$ air - acetylene flame was used throughout the work.

The flame conditions and flow injection parameters used were as follows:

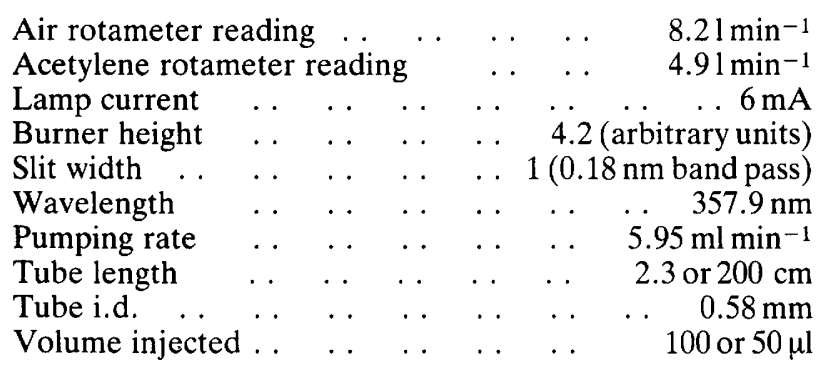

The combination of a tube length of $2.3 \mathrm{~cm}$ and with an injection volume of $100 \mu$ gave a dispersion of 1.2 and was used to analyse samples BCS $251 / 1,254 / 1$ and $255 / 1$. The combination of a tube length of $200 \mathrm{~cm}$ and an injection volume of $50 \mu \mathrm{l}$ gave a dispersion of 4 and was used to analyse samples BCS 261/1, 241/2 and 220/2.

\section{Reagents}

Chromium(III) standards were prepared by serial dilution of a 1000 p.p.m. stock solution of chromium(III) nitrate in $1 \mathrm{~m}$ nitric 
acid (BDH Chemicals). Iron(III) solution(10000 p.p.m.) was prepared by dissolving the appropriate amount of high-purity iron granules (BCS 149/3) in hydrochloric (sp. gr. 1.18) and nitric acids (sp. gr. 1.42). ${ }^{9}$

\section{Procedure}

\section{Preliminary experiments}

The optimum pumping rate ${ }^{19}$ and the variation of dispersion with tube length and volume injected for a given tube diameter were established. ${ }^{22}$ The effects of iron and acids were investigated and the effect of fuel to oxidant ratio was studied by varying the acetylene flow-rate from 4.0 to 5.5 $1 \mathrm{~min}^{-1}$ in the presence and absence of iron. For the dissolution of the samples, four different acid mixtures were investigated, namely a mixture of hydrochloric and nitric acids, ${ }^{9}$ a mixture of hydrochloric, nitric and perchloric acids, ${ }^{10}$ a mixture of sulphuric, nitric and hydrofluoric acids ${ }^{2}$ and a mixture of phosphoric, sulphuric and nitric acids. ${ }^{1}$

\section{Steel samples}

It is necessary to know the approximate ratio of iron to chromium in the final sample solution, which should contain about 10 p.p.m. of chromium. If the approximate chromium content is unknown, then a preliminary experiment is required. This also applies to the iron to chromium ratio, which should be established from a preliminary experiment or sufficient iron may be added to the final solution to ensure that the appropriate ratio is achieved.

Transfer up to $0.5 \mathrm{~g}$ into a $250-\mathrm{ml}$ PTFE beaker, add $10 \mathrm{ml}$ of hydrochloric acid (sp. gr. 1.18) and $5 \mathrm{ml}$ of nitric acid (sp. gr. 1.42). Cover the beaker with a clock-glass and heat gently until the sample has dissolved. Evaporate the solution justto dryness, cool and dissolve the residue in $10 \mathrm{ml}$ of hydrochloric acid (sp. gr. 1.18), warming to btain complete dissolution. Cool and transfer the solution, with filtration if necessary, into a $100-\mathrm{ml}$ calibrated flask. Dilute to volume with distilled water. Dilute the solution so that the final solution contains about 10 p.p.m. of chromium and either about 500 p.p.m. of iron (if dispersion 4 is used) or about 3000 p.p.m. of iron (if dispersion 1.2 is used).

Use this final solution as the carrier stream and inject standards covering the range $0-20$ p.p.m. Measure peak absorbance changes from the chart recording as either positive or negative values and plot against the appropriate standard concentration. Draw a smooth line through the calibration points and read off the concentration of the unknown solution from the intercept on the concentration axis.

\section{Results and Discussion}

The interference effect of iron is shown in Fig. 1. The degree of depression of the chromium signal increased sharply as iron was added and then levelled off at a mass ratio of iron to

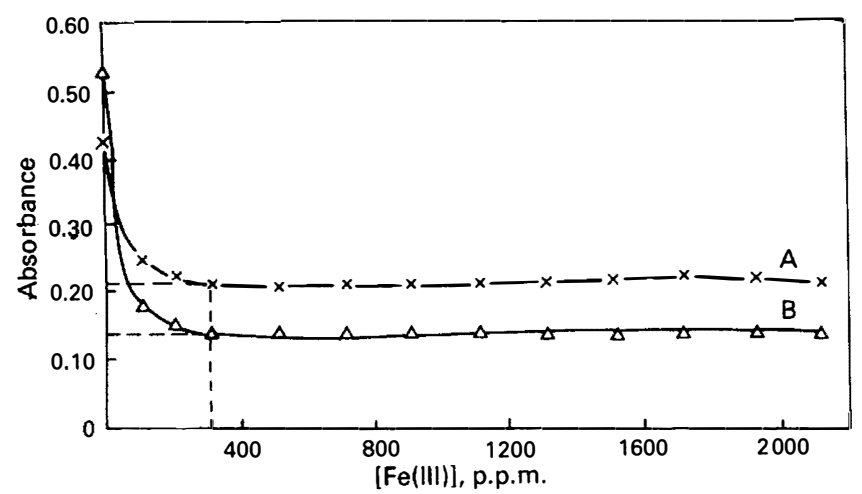

Fig. 1. Effects of iron on the absorbance of a 10 p.p.m. chromium solution. A, Fuel-lean flame; B, fuel-rich flame chromium of $30: 1$. The depressive effect was greater with a fuel-rich flame than with a fuel-lean flame.

The effects of hydrochloric and nitric acids in the presence and absence of iron are shown in Fig. 2. In the absence of iron, neither acid had much effect on the chromium signal but, in the presence of iron, the extent of the depression was not the same for both acids. The releasing effect observed with hydrochloric acid was presumably due to the formation of the metal chlorides, which have relatively low melting- and boiling-points. The effects of the other acids were complex and varied. They also depended on the presence of other cations or anions in the solution. The dissolution method of Nall et al. ${ }^{9}$ (hydrochloric and nitric acids) was judged to be the most suitable for the steels investigated in this study owing to its relatively simple effect on the chromium signal. It was also the most convenient method to use. Although a small amount of undissolved silica remained, this did not affect the accuracy of the results.

The effect of the fuel to oxidant ratio is shown in Fig. 3. The maximum signal was obtained at a fuel flow-rate of $4.91 \mathrm{~min}^{-1}$, which was a slightly luminous flame. In the presence of iron, the depression was more severe for a fuel-rich than for a fuel-lean flame.

An example of the recorder trace obtained is shown in Fig. 4 (dispersion 1.2) and the resulting calibration graph in Fig. 5. The standard deviations of the peak heights ranged from $1.4 \times 10^{-3}$ to $5.1 \times 10^{-3}$ absorbance units for the 0 and 21 p.p.m. standards, respectively. These values correspond to $0.48 \%$ and $1.20 \%$ relative standard deviation based on $\Delta A$ values. Naturally, as the concentration of standard injected approaches the concentration of the carrier stream, the relative standard deviation based on decreasing $\Delta A$ values increases. The shapes of chromium calibration graphs have been discussed by Thompson. ${ }^{17}$ The departure from the "normal" smooth curve shape observed here is in agreement with Thompson's findings, although regions of negative or

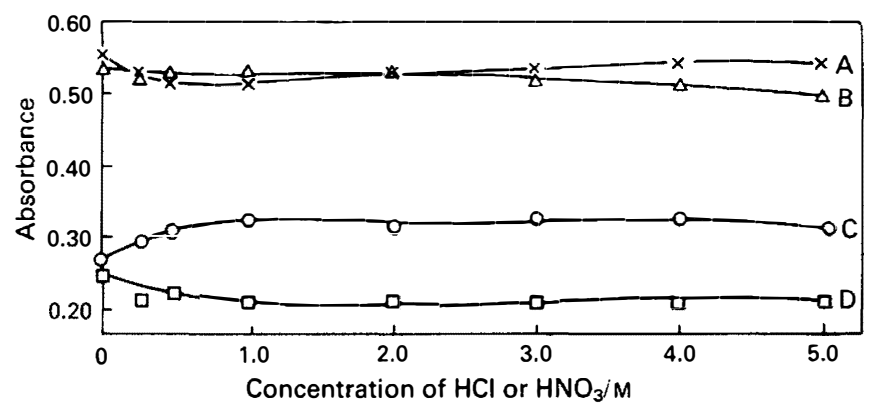

Fig. 2. Effects of acids on the absorbance of a 10 p.p.m. chromium solution in the presence and absence of iron. A, Chromium in nitric acid; $B$, chromium in hydrochloric acid in the absence of iron; $C$, chromium in hydrochloric acid; and D, chromium in nitric acid in the presence of 1000 p.p.m. of iron

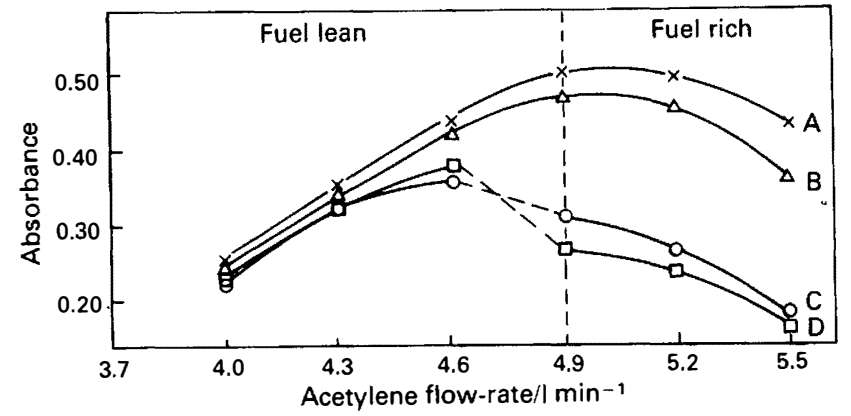

Fig. 3. Effects of fuel to oxidant ratio. A, 10 p.p.m. of chromium; B, 10 p.p.m. of chromium and 160 p.p.m. of iron; C, 10 p.p.m. of chromium and 660 p.p.m. of iron; and D, 10 p.p.m. of chromium and 1160 p.p.m. iron 


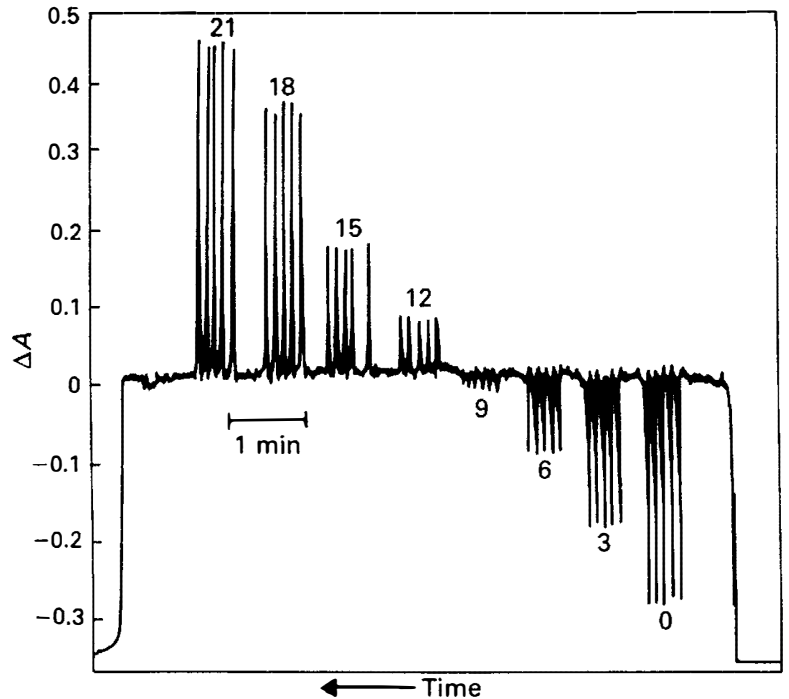

Fig. 4. Typical chart recording for the flow injection standard additions method ( $\Delta A$, change in absorbance). The steel sample contained about 10 p.p.m. of chromium and the injected standards covered the range $0-21$ p.p.m. in 3 p.p.m. increments

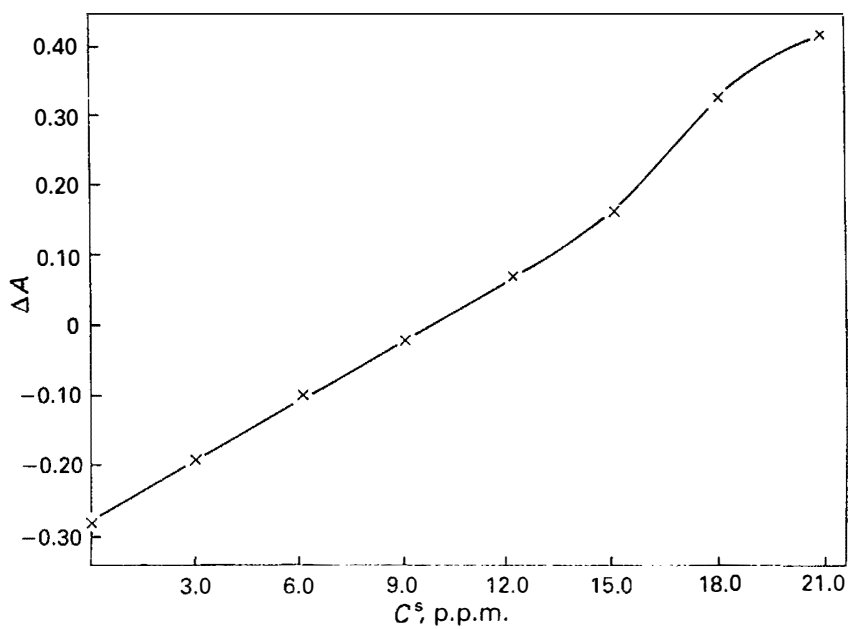

Fig. 5. Typical calibration graph for the flow injection standard addition method ( $C^{\mathrm{s}}$, concentration of standard). The sample concentration, $C^{\mathrm{x}}$, is obtained from the intercept on the $C^{\mathrm{S}}$ axis

zero slope on the calibration graph were not observed. In view of Thompson's findings and conclusions ("the determination of chromium in the luminous air - acetylene flame optimised for maximum chromium sensitivity is not recommended") and from the extent of the depression observed at this fuel to oxidant ratio in the presence of iron, it may appear that the choice of this fuel to oxidant ratio for the analyses described here is not soundly based. However, it was decided that this value should be used, as by far the easiest and commonest way of setting up an atomic-absorption instrument for the determination of any element is to set the various operating parameters to give maximum sensitivity, while nebulising a single pure standard solution of concentration calculated from the table of sensitivities in the manufacturer's handbook. The instrument would then be used for determinations in which interferences were operating without any readjustment of parameters. The results of this study show that the flow injection standard additions method can be used successfully with this setting-up strategy.

The results obtained for a number of BCS steels containing from 0.19 to $17.4 \%$ of chromium are shown in Table 1 . Additional iron was added to the first three samples to achieve the necessary $30: 1$ mass ratio of iron to chromium to give the maximum interference effect on all the standards in the
Table 1. Results for BCS steels

\begin{tabular}{llllcl}
\multicolumn{3}{c}{ Sample } & & \multicolumn{3}{c}{$\begin{array}{c}\text { Certified } \\
\text { value, } \%\end{array}$} & \multicolumn{1}{c}{$\begin{array}{c}\text { Chromium found, \% } \\
\text { BCS 261/1 }\end{array}$} & $\ldots$ & $\ldots$ & $\ldots$ & 17.4 & $17.4,17.4,17.5,17.6$ \\
BCS 241/2 & $\ldots$ & $\ldots$ & $\ldots$ & 5.35 & $5.33,5.36$ \\
BCS 220/2 & $\ldots$ & $\ldots$ & $\ldots$ & 5.12 & $5.12,5.13,5.13,5.13,5.12$ \\
BCS 251/1 & $\ldots$ & $\ldots$ & $\ldots$ & 0.51 & $0.52,0.51$ \\
BCS 254/1 & $\ldots$ & $\ldots$ & $\ldots$ & 0.27 & $0.27,0.27$ \\
BCS 255/1 & $\ldots$ & $\ldots$ & $\ldots$ & 0.19 & $0.20,0.20$ \\
\hline
\end{tabular}

calibration sequence. As the top standard contained 21 p.p.m. of chromium and the flow injection conditions were selected to give a dispersion of 4 , then the concentration of interferent in the carrier stream is calculated from equation (1) to be 525 p.p.m. for a sample concentration of half the top standard. In the experiments reported here the sample solutions were diluted so that the chromium concentration was about 10 p.p.m. and sufficient iron(III) solution was added so that the final solution contained an additional 500 p.p.m. of iron. This, together with the iron already present in the samples, was considered to provide an adequate "safety margin." As can be seen from Fig. 5, satisfactory results could have been obtained if the 15 p.p.m. standard were considered the "top" standard and so, in fact, there was a considerable safety margin. The other three samples contained a much higher ratio of iron to chromium and thus the dispersion could be decreased while still achieving the necessary maximum depressive effect. The effect of a change in top standard or sample concentrations on the concentration of interferent necessary for the successful application of the standard additions method can thus readily be calculated. Similar calculations can be performed for other interfering components of the solutions. In this study, for example, it was necessary to ensure that the effects due to the hydrochloric and nitric acids used in the dissolution procedure (see Fig. 2) were taken into account when the final acidity of the sample solutions was considered.

In theory, the equation could be used to calculate the dispersion necessary for the method to work for given values of the other parameters. Rearrangement of equation (1) gives

$$
D=\left[C_{\mathrm{t}}^{\mathrm{S}} R_{\mathrm{i} / \mathrm{a}} /\left(C_{\mathrm{m}}^{\mathrm{R}}-C \times R_{\mathrm{i} / \mathrm{a}}\right)\right]+1 \ldots
$$

The value of $D$, by definition, cannot be less than 1 , so it is immediately apparent and there is a lower limit for $C_{\mathrm{m}}^{\mathrm{R}}$ (equal to $C^{\mathrm{X}} R_{\mathrm{i} / \mathrm{a}}$ ) for successful application of the method. However, as $C_{\mathrm{m}}^{\mathrm{R}}$ approaches this limit the value of $D$ required becomes very large and there are two practical difficulties associated with large values of $D$. Firstly, the sensitivity, i.e., the slope of the calibration graph, is inversely proportional to $D$ and thus, as $D$ increases, the sensitivity decreases and the uncertainty in the interpolated value at $\Delta A=0$ (see Fig. 5) increases. Eventually, of course, at large values of $D, \Delta A$ becomes indistinguishable from the noise on the signal.

The second problem concerns the way in which dispersion is increased. If $D$ is increased by increasing the length of tubing between the injector and the nebuliser then the peak is broadened and thus the time between injections must be increased to avoid carryover and cross-contamination. If $D$ is increased by decreasing the volume injected then the precision becomes a problem as small changes in the volume injected cause large changes in the value of $D$ (see Fig. 3 in reference 22). There is also a minimum volume that can be injected owing to the mode of construction of the injection valve. There are thus a number of practical restrictions on an upper value of $D$ and so it appears sensible to select $D$ with due regard to sensitivity, peak width and precision and then to calculate the concentration of interferent required from equation (1). This may mean that interferent has to be added to samples, if the concentration is not high enough, as was done in three of the analyses reported here. 


\section{Conclusion}

In searching for solutions to analytical problems in which matrix interference effects are encountered, three approaches are, in general, applied. Either the analyte species is (a) separated literally from the interfering species prior to the final measurement step of the overall procedure, or (b) a figurative separation is achieved by the addition of selective reagents with appropriate control of reaction conditions or by appropriate use of some instrumental correction procedure or (c) the calibration procedure is designed to compensate for the interferences by ensuring that the standards are subjected to the same interferences as the samples, either by matching the standards to the samples if the nature and concentration of the interferents are known, or by standard additions if they are not. All of these approaches are used for analyses in which flame atomic-absorption spectrometry is used as the measurement stage. All of the methods have attractive theoretical features but all suffer from a number of practical disadvantages, not the least of which is the time taken to follow the method through for an individual sample. In practice, the analytical chemist uses professional skill and judgement to select the most appropriate approach for the particular problem. Generally, it appears that for the determination of minor alloying components of steels by flame atomicabsorption spectrometry, real separation methods (such as solvent extraction) are not much favoured in comparison with a combination of figurative separation (addition of releasing or protecting agents) and matching standards to samples (see, for example, reference 9). In this paper it has been shown that flow injection techniques for sample introduction to the spectrophotometer in conjunction with the design of the dispersion produced in the flowing stream (based on calculations from equations derived from the simple hypothetical well stirred mixing chamber model for dispersion) can be used to provide an alternative to the conventional standard additions method. The flow injection-based method has the advantages of requiring fewer volumetric manipulations, being less time consuming and being interpolative rather than extrapolative. The procedure developed here also allows a straightforward instrument-optimising strategy to be used and could be readily adapted to composite analytical procedures in which more than one element is determined in each sample.

Financial support for A. B. Idris from the National University of Malaysia is gratefully acknowledged.

\section{References}

1. Kinson, K., Hodges, R. J., and Belcher, C. B., Anal. Chim. Acta, 1963, 29, 134.

2. Donaldson, E. M., Talanta, 1980, 27, 773

3. Pandey, L. P., Ghose, A., Dasgupta, P., and Rao, A. S., Talanta, 1978, 25, 482.

4. Fogg, A. G., Soleymanloo, S., and Burns, D. T., Talanta, $1975,22,541$.

5. Purushottam, A., Naidu, P. P., and Lal, S. S., Talanta, 1973, 20, 631.

6. Ottaway, J. M., and Pradhan, N. K., Talanta, 1973, 20, 927.

7. Barnes, L., Anal. Chem., 1966, 38, 1083.

8. Cobb, W. D., Foster, W. W., and Harrison, T. S., Analyst, 1976, 101, 255.

9. Nall, W. R., Brumhead, D., and Whitham, R., Analyst, 1975 , $100,555$.

10. Thomerson, D. R., and Price, W. J., Analyst, 1971, 96, 321

11. Thomerson, D. R., and Price, W. J., Analyst, 1971, 96, 825.

12. Atsuya, I., Anal. Chim. Acta, 1975, 74, 1

13. Roos, J. T. H., and Price, W. J., Spectrochim. Acta, Part B, 1971, 26, 441.

14. Roos, J. T. H., Spectrochim. Acta, Part B, 1972, 27, 473.

15. Nasuta, T., Suzuki, M., and Takeuchi, T., Anal. Chim. Acta, 1970, 51, 381

16. Yanagisawa, M., Suzuki, M., and Takeuchi, T., Anal. Chim. Acta, 1970, 52, 386

17. Thompson, K. C., Analyst, 1978, 103, 1258.

18. Green, H. C., Analyst, 1975, 100, 640.

19. Tyson, J. F., Anal. Proc., 1981, 18, 542.

20. Tyson, J. F., and Idris, A. B., Analyst, 1981, 106, 1125.

21. Tyson, J. F., Appleton, J. M. H., and Idris, A. B., Anal. Chim. Acta, 1983, 145, 159.

22. Tyson, J. F., Appleton, J. M. H., and Idris, A. B., Analyst, 1983, 108, 153. 